\title{
Paraplegia
}

\section{Post-traumatic Syringomyelia, an Update}

\author{
B. Williams, MD, ChM, FRCS \\ Midland Centre for Neurosurgery and Neurology, Warley, UK.
}

\begin{abstract}
Summary
Post-traumatic and post-arachnoiditic syringomyelia is described in 31 patients from the Midland Centre for Neurosurgery and Neurology (MCNN). It is suggested that the mechanisms may be similar in the two groups and that treatment is best directed to disabling the likely filling mechanisms by opening up the cerebrospinal fluid (CSF) pathways and deliberately leaving the dura open to create an artificial meningocele. It is suggested that drainage on its own is inappropriate but that when drainage of the syrinx is chosen as an ancillary technique then syringopleural drainage may be the procedure of choice.
\end{abstract}

Key words: Spinal cord injuries; Syringomyelia; Arachnoiditis; Post-traumatic cystic myelopathy.

Since the presentation of 10 cases of post-traumatic syringomyelia to the IMSOP (Williams et al., 1981) further cases have been seen. The majority of these have been cases with complete or partial paraplegia. Because of the important similarities, the blockage of the CSF pathways around the cord, the upward extension of the syrinx cavities, particularly in association with straining and the tendency to progress, sometimes many years after the causative lesions, it seems probable that the mechanism of the syringomyelia is often similar in both the post-traumatic and the post-inflammatory types of case. The main difference between them seems to be that in some of the post-traumatic cases the condition becomes evident early, only a few months after the initial cord involvement. This may be a manifestation of a supposed haematoma at the site of injury. This possibility is largely unexplored at present and it is therefore not possible to separate the cases retrospectively. Thirty one cases are presented with 7 of them being non-traumatic and the principles of treatment discussed for both types together. Initial results of treatment have been disappointing and have lead to emphasis in surgical management being placed on prevention of the filling mechanisms and the replacement of syringosubarachnoid shunting by more forceful methods of drainage using shunting from syrinx to extrathecal sites, the pleural cavity being chosen in the more recent cases 
in this series. The diagnosis in this small series has been done mainly on clinical grounds, the index of suspicion having been markedly raised over the past 10 years with earlier referrals becoming more common. The principal misdiagnoses have concerned cervical spondylosis, carpal tunnel syndrome and ulnar nerve compression at the elbow, all of which may be more common in the paraplegic than in the normal population. Radiological confirmation has been by myelography, endomyelography, post-myelography CT examinations and more recently by MRI examination. There is a limited value in extensive radiological studies, a careful exploration yields more information about the nature of the local arachnoiditis, which is one of the most important features and difficult to assess radiologically. MRI has therefore often been omitted, but has proved to be of singular value in outpatient surveillance. Points of technique, results and illustrative cases are presented.

In looking back over the past 7 years, during which time cases of syringomyelia related to primarily spinal disease have continued to be seen at the Midland Centre for Neurosurgery and Neurology, it has been difficult to investigate any specific kinds of presentation, methods of investigation or particular methods of treatment and to compare them against any other. This is because the cases are so variable in their severity, natural history, associated neurological disorders and in the response to treatment, that the categorisation of the cases makes almost every case unique. Comprehensive reviews have come from Rossier et al. (1968), Barnett and Jousse (1976), Lacert et al. (1977), Shannon et al. (1981), Vernon et al. (1983) and Rossier et al. (1985). Additionally a number of personal cases have been seen who were not fully investigated, usually because they were not considered for operative treatment.

The propositions of the earlier paper are re-examined in the light of subsequent experiences and possible new interpretations discussed.

\section{Case material}

In addition to the 10 cases described briefly in the 1981 paper a further 21 cases have been seen and investigated. A breakdown is given in Table I which includes the earlier material. Table II shows cases with intradural and subarachnoid adhesions which are the late results of arachnoiditis.

Table I Traumatic cases

\begin{tabular}{|c|c|c|c|c|c|c|c|c|c|}
\hline \multicolumn{5}{|c|}{ Paraplegia } & \multicolumn{4}{|c|}{ Syringomyelia operations } & \multirow[b]{2}{*}{ Result of last operation } \\
\hline$\overline{\text { Case }}$ & Sex & Age & Level & $\mathrm{P} / \mathrm{C}$ & Age & Level & Age & Type & \\
\hline 1 & $\mathbf{M}$ & 20 & L2 & $\mathbf{P}$ & 21 & T9-L2 & 43 & $\begin{array}{l}\text { DEC, } \\
\text { BYP }\end{array}$ & $\begin{array}{l}\text { Improvement in syrinx } \\
\text { features and long tract } \\
\text { function, stable }\end{array}$ \\
\hline 2 & $\mathbf{F}$ & 21 & T5 & C & 22 & M-T7 & 39 & $\begin{array}{l}\text { TRA, } \\
\text { SPL }\end{array}$ & $\begin{array}{l}\text { Improvement in syrinx } \\
\text { features, stable }\end{array}$ \\
\hline 3 & $\mathbf{F}$ & 47 & T4 & C & 51 & C3-T4 & 57 & SSA & $\begin{array}{l}\text { Improvement in sensation and } \\
\text { back, power stable for } 10 \\
\text { years }\end{array}$ \\
\hline 4 & $\mathbf{M}$ & 24 & $\mathrm{C7}$ & $\mathrm{C}$ & 26 & C2-T8 & 26 & See text & See text \\
\hline 5 & $\mathbf{M}$ & 17 & T5 & $\mathrm{C}$ & 20 & M-T? & 34 & $\begin{array}{l}\text { TRA, } \\
\text { SPL }\end{array}$ & Some improvement. See text \\
\hline
\end{tabular}


(Table I continued)

\begin{tabular}{|c|c|c|c|c|c|c|c|c|c|}
\hline \multicolumn{5}{|c|}{ Paraplegia } & \multicolumn{4}{|c|}{ Syringomyelia operations } & \multirow[b]{2}{*}{ Result of last operation } \\
\hline Case & Sex & Age & Level & $\mathrm{P} / \mathrm{C}$ & Age & Level & Age & Type & \\
\hline 6 & $\mathbf{M}$ & 21 & T7 & $\mathbf{P}$ & 27 & C4-T? & 27 & SPL & $\begin{array}{l}\text { Resolution of syrinx } \\
\text { symptoms, stable, } \\
\text { R collapsed }\end{array}$ \\
\hline 7 & $\mathbf{M}$ & 19 & T6 & $\mathrm{C}$ & 21 & $\mathrm{Cl}-\mathrm{T}$ ? & 21 & SPL & $\begin{array}{l}\text { Initial improvement, } \\
\text { worsening of pain, later } \\
\text { deterioration }\end{array}$ \\
\hline 8 & $\mathbf{M}$ & 32 & C6 & $\mathrm{C}$ & 34 & $\mathrm{Cl}-\mathrm{T} 2$ & 36 & SPL & $\begin{array}{l}\text { Improvement in power and } \\
\text { sensation, stable }\end{array}$ \\
\hline \multirow[t]{2}{*}{9} & $\mathbf{M}$ & 18 & $\mathrm{~T} 1$ & $\mathrm{C}$ & 30 & Cl-T? & 36 & SPL & $\begin{array}{l}\text { Two cavities shunted } \\
\text { separately, good result, } \\
\text { then deterioration }\end{array}$ \\
\hline & & & & & & & 37 & SPL & $\begin{array}{l}\text { One hand improved the other } \\
\text { worsened }\end{array}$ \\
\hline 10 & $\mathbf{M}$ & 23 & C6 & $\mathbf{P}$ & 26 & C2-T? & 42 & SPL & $\begin{array}{l}\text { Slight improvement, later } \\
\text { deterioration, collapse of } \\
\text { syrinx }\end{array}$ \\
\hline 11 & $\mathbf{M}$ & 17 & T4 & C & 20 & C1-T? & 31 & SSA & Stable \\
\hline 12 & $\mathbf{M}$ & 28 & T12 & $\mathrm{C}$ & 32 & C1-L1 & 34 & SSA & Stable after improvement \\
\hline 13 & $\mathbf{F}$ & 29 & T6 & $\mathrm{C}$ & 39 & C2-T? & 43 & TRA & $\begin{array}{l}\text { Marked improvement, } \\
\text { stability }\end{array}$ \\
\hline 14 & $\mathbf{M}$ & 41 & T5 & C & 42 & $\mathrm{Cl}-\mathrm{T}$ ? & 43 & SPL & Improvement, stable \\
\hline 15 & $\mathbf{M}$ & 21 & T9 & $\mathrm{C}$ & 25 & C3-T11 & 29 & SPL & $\begin{array}{l}\text { Some improvement, some } \\
\text { new symptoms, chest pain } \\
\text { and arm paraesthesia }\end{array}$ \\
\hline 16 & $\mathbf{M}$ & 25 & T4 & $\mathbf{P}$ & 31 & T3-T5 & 36 & DEC & $\begin{array}{l}\text { Marked improvement in the } \\
\text { legs, later deterioration }\end{array}$ \\
\hline 17 & $\mathbf{F}$ & 44 & $\mathrm{~T} 8$ & $\mathrm{C}$ & 46 & M-Ll & 60 & $\begin{array}{l}\text { TRA, } \\
\text { SPL }\end{array}$ & $\begin{array}{l}\text { Collapse of syrinx, severe pain } \\
\text { persisted and worsened }\end{array}$ \\
\hline 18 & $\mathbf{M}$ & 17 & $\mathrm{~T} 2$ & $\mathbf{P}$ & 29 & M-T9 & 36 & SPL & $\begin{array}{l}\text { Improved, short review } \\
\text { period so far }\end{array}$ \\
\hline 19 & $\mathbf{M}$ & 22 & L1 & C & 32 & C?-L1 & 40 & SSA & Stable after improvement \\
\hline 20 & $\mathbf{M}$ & 21 & $\mathrm{~T} 1$ & $\mathbf{P}$ & 37 & C2-T6 & 51 & SPL & $\begin{array}{l}\text { Worsening of one arm, pain } \\
\text { improved, late worsening } \\
\text { of all. R Cord collapsed }\end{array}$ \\
\hline 21 & $\mathbf{M}$ & 22 & L1 & $\mathrm{C}$ & 23 & C?-L1 & 24 & TV & $\begin{array}{l}\text { Great improvement, then } \\
\text { advance of symptoms with } \\
\text { change of side }\end{array}$ \\
\hline & & & & & & & 28 & SPL & Stable \\
\hline 22 & $\mathbf{M}$ & 20 & $\mathrm{~T} 4$ & $\mathrm{C}$ & 32 & C?-T? & 36 & SSA & $\begin{array}{l}\text { Radiologically perfect, power } \\
\text { improved to perfect, } \\
\text { continued pain }\end{array}$ \\
\hline 23 & $\mathbf{M}$ & 22 & L1 & $\mathrm{C}$ & 40 & C3-L2 & 47 & SSA & Improved \\
\hline 24 & $\mathbf{M}$ & 36 & T4 & $\mathrm{C}$ & 37 & C?-T? & 37 & SPL & Markedly improved \\
\hline
\end{tabular}

P: Partial; C: Complete; SSA: Syringo-subarachnoid; SPL: Syringopleural; TRA: transection; DEC: only decompression; TV: Terminal ventriculostomy (excision of filum terminale); BYP: Bypass shunt tubes from the subarachnoid space to the artificial meningocele, above and below the block; R: postoperative radiological investigation $\mathrm{M}$ : Male or medulla.

This group of patients have diverse features, and statistical analysis of their behaviour seems inappropriate. One possibly significant feature is that of the 24 post-traumatic cases there were 17 with an onset within 7 years of the trauma and the remaining 7 came on after 10 years, thus resembling the non-traumatic ones. The immediate cause in case 2 was not known and thus not datable. However of the other 6 cases the mean age of onset was $12 \cdot 5$ years after the presumed cause. Some of the case histories are given in more detail. 
Table II Arachnoiditis cases

\begin{tabular}{|c|c|c|c|c|c|c|c|c|}
\hline Case & Sex & $\begin{array}{l}\text { Age at } \\
\text { disease }\end{array}$ & Disease & $\begin{array}{l}\text { Age at } \\
\text { syrinx }\end{array}$ & $\begin{array}{l}\text { Level of } \\
\text { syrinx }\end{array}$ & $\begin{array}{r}\mathrm{O} \\
\text { Age }\end{array}$ & $\begin{array}{l}\text { eration } \\
\text { Type }\end{array}$ & \\
\hline 1 & $M$ & $?$ & Idiopathic & 37 & $\mathrm{~T} 4$ & 39 & DEC & $\begin{array}{l}\text { No great change, } \\
\text { possibly some long } \\
\text { tract gains }\end{array}$ \\
\hline 2 & $\mathbf{F}$ & 8 & TB Men & 27 & C?-L? & 30 & $\begin{array}{l}\text { SYR, } \\
\text { SUB }\end{array}$ & $\begin{array}{l}\text { Developed total } \\
\text { paraplegia after } \\
\text { second operation }\end{array}$ \\
\hline 3 & $\mathbf{M}$ & 27 & Cord Abscess & 38 & C3-L1(?) & 49 & SSU & $\begin{array}{l}\text { Initial deterioration in } \\
\text { the legs, then } \\
\text { improved }\end{array}$ \\
\hline 4 & $\mathbf{M}$ & 6 & Meningitis & 38 & T6-T12 & & & $\begin{array}{l}\text { No operation advised, } \\
\text { see text }\end{array}$ \\
\hline 5 & $\mathbf{F}$ & 52 & SAH, Myodil & 63 & T2-L1 & 64 & DEC & $\begin{array}{l}\text { Not possible to open } \\
\text { the dura, no change }\end{array}$ \\
\hline \multirow[t]{2}{*}{6} & $\mathbf{M}$ & 34 & Lam, Myodil & 44 & C5-Co & 44 & SPL & $\begin{array}{l}\text { Striking improvement, } \\
\text { followed by } \\
\text { deterioration }\end{array}$ \\
\hline & & & & & & 45 & SPL & $\begin{array}{l}\text { Improvement in sacral } \\
\text { sensation with worse } \\
\text { pain }\end{array}$ \\
\hline 7 & $\mathbf{M}$ & 12 & TB Men, Spine & 16 & $\mathrm{Cl}-\mathrm{T} 8$ & 17 & $\begin{array}{l}\text { DEC, } \\
\text { BYP }\end{array}$ & $\begin{array}{l}\text { Improvement, } \\
\text { antituberculous } \\
\text { treatment. See text }\end{array}$ \\
\hline
\end{tabular}

SAH: subarachnoid haemorrhage; Men: meningitis; TB: tuberculosis; Myodil: pantopaque; Lam: laminectomy; Co: conus; Lam: laminectomy

\section{Case 1}

Post-traumatic partial paraplegia at $\mathrm{Ll}$ in a 20 -year-old man who had little deficit apart from weakness of quadriceps on one side (Table I). He suffered neurological deterioration starting 1 year later. Spinal fusion was performed. Neurological function continued to deteriorate and a laminectomy was done. The only finding was adhesive arachnoiditis. The dura was closed. The patient was worse afterwards and continued to deteriorate. When seen in MCNN at the age of $\mathbf{4 2}$ he had had a sympathectomy for hyperhidrosis. There was progressive loss of muscle bulk and power in the buttocks and left calf. His bladder function was almost gone, he had severe proprioceptive loss in both legs and severe loss of all sensory modalities in the left leg. The neurological level for dissociated sensory loss had ascended up the abdomen on the left side to T10. MRI scanning failed to show a syrinx but myelography showed a cyst at the level of the fracture with free communication to the subarachnoid space below the zone of arachnoiditis (Fig. 1). Post-myelography CT showed a big densely opacifying syrinx extending above the small cyst as far as T9 (Fig. 2). Operation intending to drain the syrinx failed because the adhesions were so dense and the anatomy of the cord so distorted that the cavity was not successfully needled or found after myelotomy. A bypass tube was inserted from the subarachnoid space above the adherent zone to that below (Fig. 6). Despite having had a difficult exploration and two myelotomies to try to find the syrinx, the patient was immediately improved, particularly the sensory loss from the level of the lesion to T10. The bladder function remained critical, walking was unchanged. He has subsequently developed more pain, especially in the left leg.

\section{Case 2}

Complete paraplegia at T5 in a 21-year-old woman (Table I). Two years after the accident she noticed pain accompanied by sensory changes progressing up the left side from the level of the lesion to the side of the face. The arm jerks were depressed on the left, there 


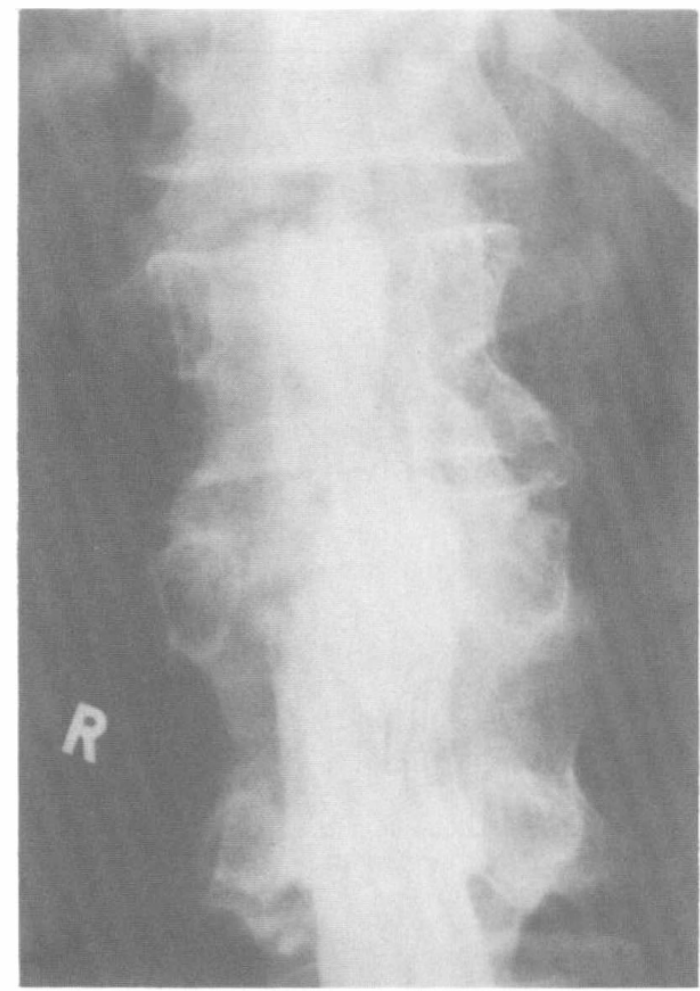

Figure 1 Case 1. The myelogram from below seems to fill a small syrinx directly, but no contrast passes upwards beyond the level of the lower border of $\mathrm{T} 12$.
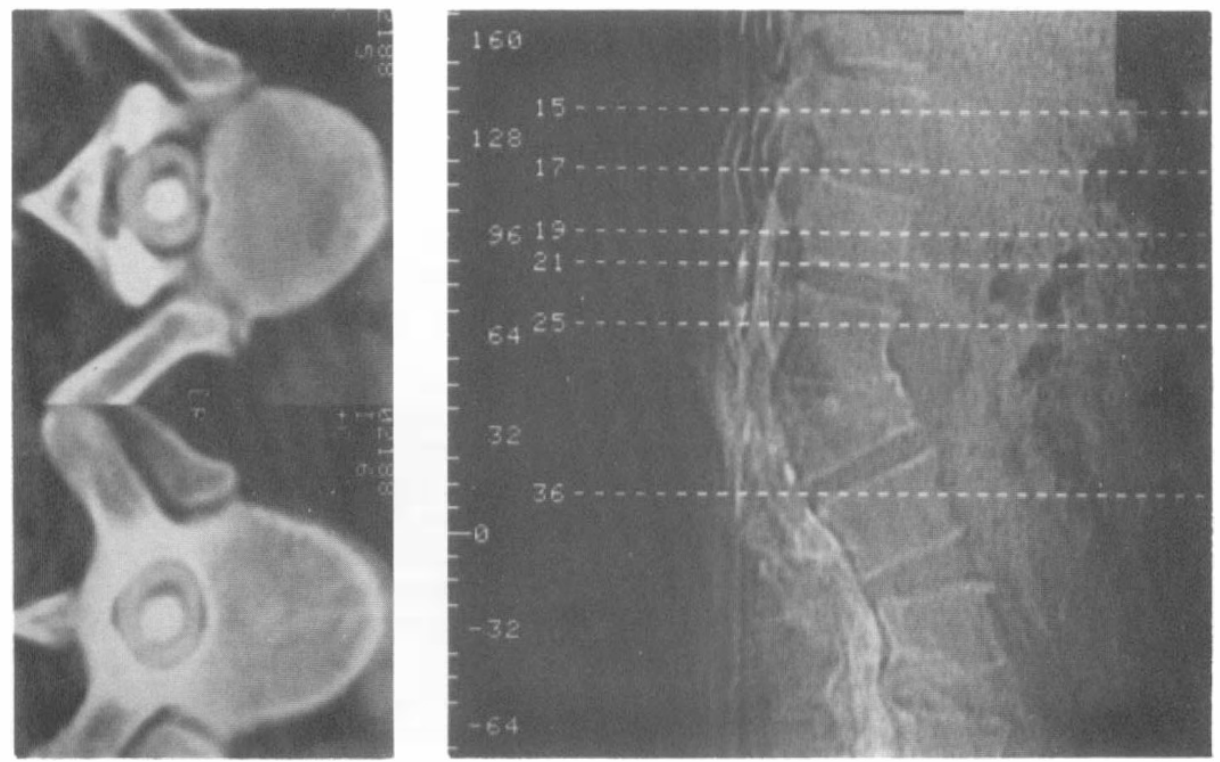

Figure 2 Case 1. The post-myelography CT scan after some hours shows that there is a low concentration outside the cord and a dense opacification of a tight looking syrinx up to the T9 level. Two cuts are shown at T11. 
was no loss of power or dexterity and no pain. Syringomyelia was diagnosed and the patient advised to cut down physical activity. She was a well-adjusted, working and stable paraplegic for 15 years thereafter, when she was involved in a second car crash. There was immediate neck pain and increase of spasms followed shortly by deterioration of sensation of the left upper forequarter, loss of dexterity, dropping of objects from both hands and deterioration in her handwriting. The sensation continued to deteriorate on the left side with accompanying spasticity on the right. She required help with transfers and with dressing. She had to stop work. Investigations confirmed a syrinx with haustrae extending up to the medulla and down to T7.

Cord transection was done with excision of a part of the cord and a shunt from the upper part of the syrinx to the pleura (Fig. 6).

The post-operative result was pleasing with a steady improvement in power and ability to transfer. The MRI appearance of the syrinx was improved. She was able to resume some of her hobbies and to go back to work, although the sensory loss was not much improved.

\section{Case 3}

Tuberculous meningitis in a 38-year-old man was treated with intrathecal streptomycin (Table II). He had some residual cord signs and urinary incontinence but he recovered sufficiently well to return to work. The cord function deteriorated markedly 4 years after the illness with progressive leg weakness, pain in the trunk, loss of bladder and bowel control and diminution of all sensory modalities below T3. Dense arachnoiditis was shown from T2 downwards. After a further 4 years the paraplegia was complete and the deficits had spread to the arms with loss of small muscles of the hand and tendon reflexes on the right, paraesthesiae and sensory loss involving the right forequarter up to C2. Postmyelography CT showed a cord cavity from C2 to the lower thoracic region, the cavity was maximal in the $\mathrm{C} 4-\mathrm{C} 7$ cervical enlargement. Syringopleural shunt made no difference to his clinical state, the arms continued to deteriorate with decubitus ulceration and severe contractures. He died 2 years after his last admission.

\section{Case 4}

A 23-year-old man sustained complete paraplegia at C7, incomplete up to C5 (Fig. 3, Fig. 4). He was subject to severe neck pain with weakness spreading into the left upper arm 16 months after the original injury and was initially treated elsewhere. He developed loss of sensation on the left from C5 downwards. A large cervical syrinx (Fig. 1) was drained by a syringopleural shunt 16 months after the paraplegia. There was immediate improvement but he developed a CSF leak. At re-exploration the shunt tube was found to have come out and the previous myelotomy was seen to be open and was left alone. The dura was closed. The arm power improved for a while but 20 months after the operation he was again deteriorating. He had a further scan and recurrence of the cyst was seen. At a third operation, 21 months after becoming paraplegic, a small cyst was found and drained to the peritoneum. Further investigation showed that there was a big cyst above the drainage tube. At a fourth operation 3 weeks later, the tube was advanced upward into the main cyst. He again improved for a while but then had a sudden deterioration associated with straining in which he lost the greater part of the lower arm function on the right. MRI scanning showed a further or persistent cyst (Fig. 2). At a fifth operation in MCNN $2 \frac{1}{2}$ years after the paraplegia the arachnoiditis was extensively unpicked. The peritoneal shunt was repositioned and shortened so that it worked again. A further drain was inserted into the small cavity at the bottom of the cord by transecting and excising a small piece of the cord (Fig. 6). The lower end of this drain went to the pleural space. The dura was stitched widely open to minimise adhesion. There was some improvement in the upper arm function, the triceps, forearm and hand on the right remained substantially paralysed with some residual pronation and long tendon extension. There remained severe sensory loss and some weakness on the left. He was largely stable after the fifth operation, for a further 6 months, but further slow deterioration has occurred with no evidence of syrinx recurrence. 


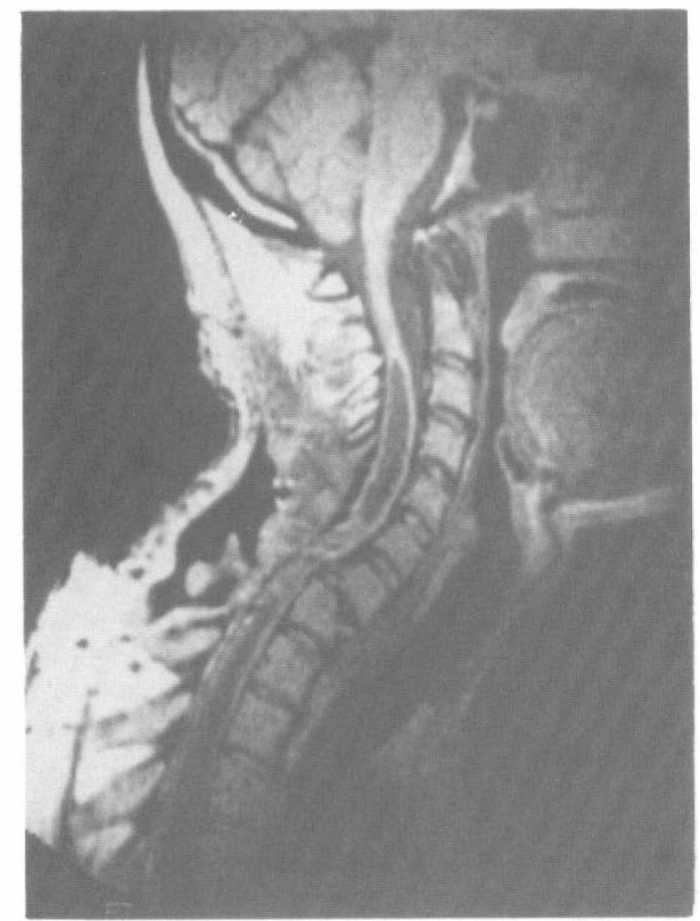

Figure 3 Case 4. Appearances before shunting, note the constriction at the level of the fracture with no visible communication between the lower and the upper cavities. A communication is often evident at surgery in such cases and the shunting of the symptomatic cavity alone is not adequate.

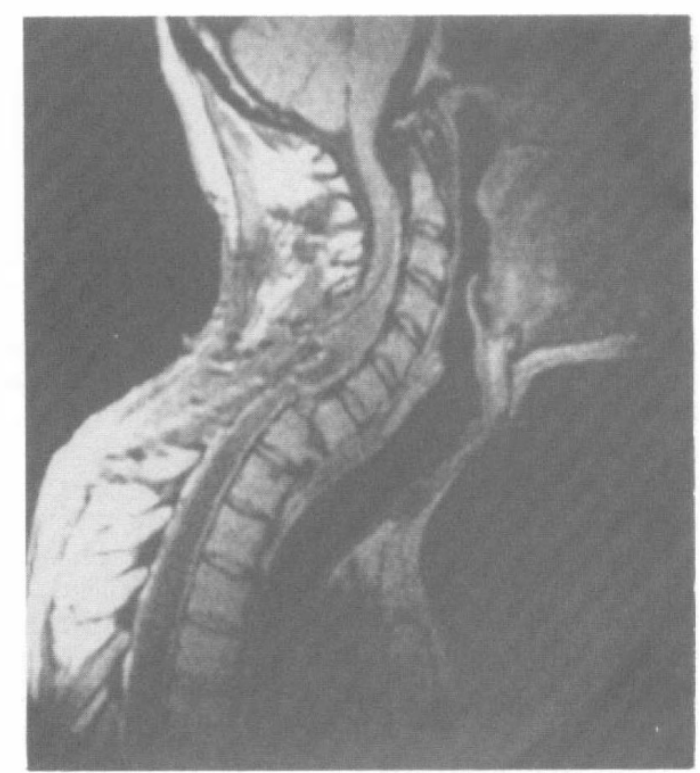

Figure 4 Case 4. Appearances after shunting of the upper cavity and closure of the dura, leaving the lower cavity alone. Note that the cord is once more enlarged and the upper drain is evidently not working despite the correct position. The cavity had redeveloped fully at the time of the fifth operation and was redrained. 


\section{Case 5}

Complete paraplegia at age 17 at T6 in a man with a strong family history of epilepsy (Table I). He was well rehabilitated until age 20 when he developed sensory loss in the right arm. There was an associated pain in the right arm so severe that he was admitted to hospital. The right arm jerks were depressed and syringomyelia was diagnosed. As the pain recovered the arm came back to full power and operative treatment was not advised. The right arm gradually lost more motor and sensory function. At the age of 34 he was involved in a road traffic accident. He had accelerated decline in the use of the right arm and lost the ability to transfer into his car. There was marked wasting of the intrinsic hand muscles, the arm reflexes went from both sides and there was bilateral sensory impairment below C5. Investigations showed a syrinx ascending to the medulla and tapering off a few segments below the cord trauma.

An operation was done to resect a small part of the cord and to make an artificial meningocele. The immediate post-operative course was complicated by fits and some mental disturbances which passed after a few days. The neurological status was slightly improved 6 months after operation with increased independence and improved transfers.

\section{Case 6}

A 6-year-old boy was treated for pyogenic meningitis in 1946 by the use of intrathecal sulphonamides (Table II). He had severe lower motor neurone losses and sensory loss in the lower legs and developed pes cavus and trophic changes. He had little difficulty walking and the remainder of the nervous system was normal until aged 38 when he had severe lumbar pain extending up the left side of the trunk accompanied by sensory loss up to T6. Minor subjective sensory changes reached to C6 on the left. At the age of 40 the losses increased and spread to the right lower costal region and the right leg. At the age of 46 he was straining to pick up a big motorcycle when he fell. There was immediate loss of power and sensation in both legs mostly affecting the right side. Power slowly improved but this was incomplete and his legs remained fatigueable. He had an asymmetry of sweating up to the hands and armpits. Power and reflexes were normal in the arms. MRI scans showed a cavity from $\mathrm{T} 10$ to $\mathrm{L} 1$. The overall cord dimensions were normal. Operation was not advised.

\section{Case 7}

A 12-year-old boy had tuberculous meningitis and Potts paraplegia with vertebral involvement at T8-9 (Table II). A costotransversectomy and bone grafting had been carried out.

After extensive chemotherapy he achieved a stable state and at the age of 16 he had the onset of left sided abdominal pain radiating into the left hip. A syrinx was opacified from $\mathrm{Cl}$ to below the gibbus on post-myelographic CT. The CSF was pleocytic and proteinous so a course of antituberculous therapy was reinstituted. This seemed to produce some improvement and operation was delayed. His condition varied somewhat thereafter with an intermittent limp, and therefore operation was planned with the intention of bypassing the zone of maximal arachnoiditis. The small size of the syrinx and the previous pleural involvement together with the good cord function meant that the likelihood of performing a syringopleural shunt was not thought probable.

At laminectomy, aspiration of the cord cyst yielded opalescent fluid with tubercle bacilli present in fluid from three levels. The protein content was $0.84,0.4$ and $0.74 \mathrm{~g} / 1$ from above downwards at the three sites. Separate tubes were inserted from the subarachnoid spaces above and below respectively to the artificial meningocele as in Figure 6 .

There was no immediate deterioration in the neurological status, antituberculous treatment was started. Post-operative MR scanning showed that the upper part of the syrinx from the level of the laminectomy up to the top of the cervical spine was completely collapsed, but the lowermost part of the syrinx remained tense. 


\section{Case 8}

A 32-year-old male rugby player sustained a burst fracture of $\mathrm{C} 5$ with a complete paraplegia at $\mathrm{C} 6$ neurological, higher on the right with loss of all motor functions below the elbow except for a little dorsiflexion of the wrist (Table I). Two years after good rehabilitation he had slight weakness of the right upper arm manifested by a tendency for his wheelchair to veer to the right. He also tended to lean over to the right whilst sitting, especially driving. No weakness of muscles innervated from higher in the cord was demonstrable on dynamometry. Some numbness and paraesthesiae developed on the right side of the neck, going up to the lower part of the face and $\mathrm{C} 2$ distribution on the back.

Myelography showed a partial block at the level of the fracture with relatively easy passage of the contrast medium past the involved level. The cord was not enlarged. Postmyelography CT showed a syrinx from $\mathrm{C} 1$ to $\mathrm{T} 2$, biggest at $\mathrm{C} 3-\mathrm{C} 4$.

Laminectomy from $\mathrm{C} 3$ to $\mathrm{T} 1$ allowed dissection of the cord from the dura. The dura was stitched back. The cord was very translucent and waterlogged. It was impossible to see where the cord was sufficiently intact for function. Transection was therefore avoided. A syringopleural drain was inserted for a distance of $3 \mathrm{~cm}$, septation prevented further introduction, and as this was done the subarachnoid space above the site or the primary lesion opened up fully so that it seemed adequate to disable the filling mechanism. The distal end was placed in the right pleural cavity. The dura was left open.

The post-operative course was complicated by headache, neck stiffness and pyrexia with sweating. No positive cultures were obtained from a pleocytic CSF but after antibiotics the patient became perfectly well. Sensation largely recovered in the neck, motor improvement was not assessable.

At outpatient assessment after 3 months the patient reported continuing improvement, facial sensation was normal as was the power previously lost which had apparently been due to the syrinx.

\section{Case 9}

An 18-year-old man suffered complete traumatic paraplegia at $\mathrm{T} 1$. The small muscles of the hands were intact until the age of 30 when wasting became visible on the left (Table I). There was an associated sensory loss. The condition progressively advanced with bilateral involvement but no pain. At age 36 syringopleural shunting was planned. The cavities above and below the initial damage were separate. They were therefore drained separately. The lower cavity accepted a $10 \mathrm{~cm}$ catheter, but the upper one stopped at $3 \mathrm{~cm}$, due to septation which could not easily be bypassed. Damage to the cervical enlargement was feared, it was thought probable that the drainage of the two cavities would be enough to hold the filling mechanism and the dura was closed. There was no initial improvement, the sensation seemed to be slowly deteriorating and weakness of both hands was progressing so that he could no longer hold a table tennis bat.

Repeat investigation showed that the syrinx above the top drain was still full and tense. The cord was re-exposed and a midline myelotomy made above the tip of the catheter. A longer catheter was inserted for $8 \mathrm{~cm}$ and the upper syrinx thereby collapsed.

Post-operative recovery was markedly better than after the first operation, despite some increased sensory loss in the left hand, the thumbs regained the power of opposition on both sides so that he could once more hold his bat, winning two silver medals at the next games.

\section{Results}

The results are disappointing in terms of recovery of lost function. Distinct improvement was often seen but no severe weakness was reversed. There have however, been no deaths attributable to operation and no major morbidity. One patient (case 20) had deterioration of arm power directly after resuturing of a 
wound which broke down. One patient broke down a pre-existing bedsore, one post-traumatic (case 5) went into status epilepticus, another had some form of severe metabolic disturbance the nature of which was not determined but which was followed by recovery (case 11). Recommended stages in the operation are shown in Figures 5 to 8 .

Failure to control the pain is a disappointing feature, despite encouraging reports from Shannon et al. (1981) and Suzuki et al. (1985), indeed some of the patients have reported an exacerbation of the pain in an area which was previously numb but not painful (cases 7,17 , and 20). It may be that the return of cord function in the substantia gelatinosa is responsible for this. The majority of such patients find that the pain eases after a while.

Several cases have required reoperation for the progression of symptoms, one other (case 15) has been similar to post-traumatic case 4 in development of symptoms on the opposite side after apparently successful drainage but has declined further investigation. Case 21 had change of sides in association with relapse prior to a second operation. Case 9 needed the drainage tube to be moved upwards as a second operation. Similarly the arachnoiditic case 6 needed a separate drainage for the lower part of the cord after the upper part had apparently been successfully drained. No case has required reoperation after transection of the cord. No case has required reoperation since the principle of widely opening the dura and leaving it open has been followed.

Another disappointing feature has been the progression of deterioration after the performance of surgery with apparently good syrinx control. The nature of the dense adhesive arachnoiditis at the site of partial lesions in patients such as post-traumatic cases 1,4 , and 10 may well lead to progressive loss even if the syrinx had not formed. Likewise the multiple interventions in case 20 (Fig. 9) may lead to progressive loss of function even if the syrinx remains undetectable. Similarly the widespread scarring, both collagenous and gliotic in the arachnoiditic cases, in TBM case 3 leading on to death, are not unexpected and do not reflect badly on the surgery so much as the intractable nature of the basic condition. It is notable that in regular hindbrain related cases without any inflammatory changes around the outside of the cord, then the progression of neurological symptoms with age is quite common, either due to progressive gliosis or to other varieties of ageing being exaggerated in the damaged cord.

\section{Discussion}

\section{Pathogenesis}

The origin of the cavity which initiates post-traumatic syringomyelia remains unclear. The suggestion that there was originally a cavity formed by liquefaction of cord tissue or by the accumulation of a haematoma which then liquefied remains attractive. That might explain some cases where the protein is high or is different in differing loculi of the syrinx. In the post-arachnoiditic cases however there has been no sudden trauma and the neurological deterioration has been gradual and sometimes may have occurred where the syrinx had already reached a large size. The pathogenesis in these post-arachnoiditic cases is therefore not that of prior liquefaction and the explanation remains elusive. One notion is that the back and 
306 PARAPLEGIA
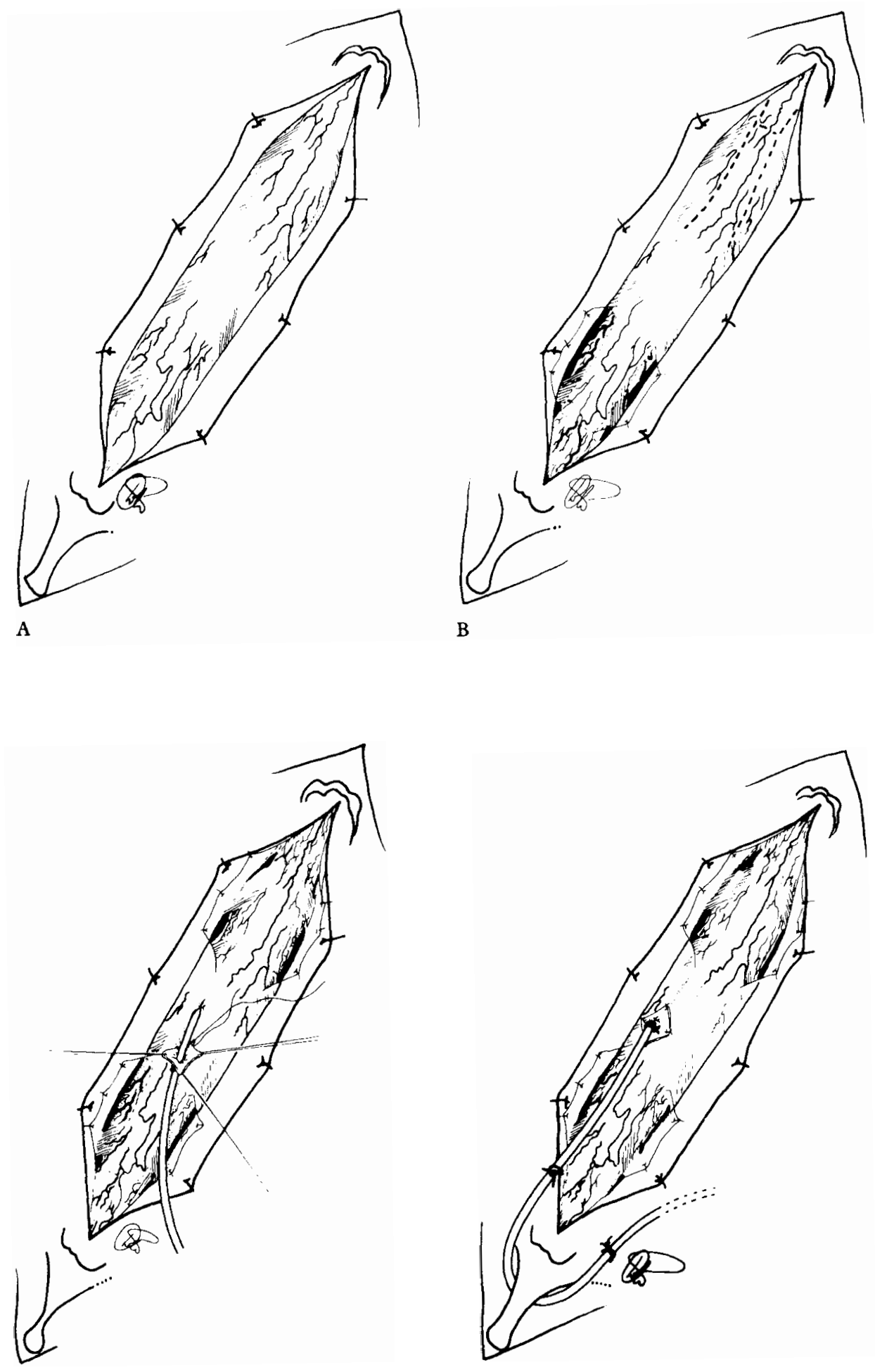

C

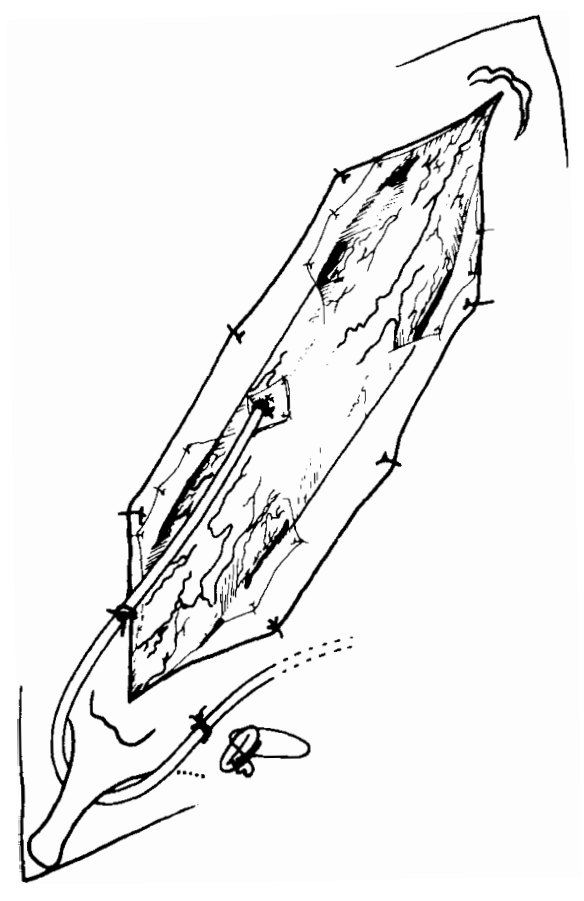

D 
Figure 5 Suggested sequence of steps for surgical treatment of syringomyelia secondary to adhesive arachnoiditic changes.

(A) The opening should be large, enough to reach normal cord above and below in post traumatic cases although this may not be feasible with non-traumatic adhesions because of the extent of the arachnoiditis. The dura should be carefully sutured back to allow the leaving behind of an artificial meningocele.

(B) The opening of the arachnoid and its careful suturing to the dura is important. There is little value in opening it up to the midline, a lateral opening is best for achieving the subarachnoid space. Careful suturing of the arachnoid to the dura may hold the subarachnoid space open. The opening of the subarachnoid space is also helped by collapsing the cord by a syringopleural shunt.

(C) If the syringopleural shunt is chosen a myelotomy site may usually be selected with the pia thickened enough to take sutures and very little vascularity. There may be difficulty in passing the catheter upwards because of strong septation. In complete paraplegia the incision may be taken quite high in the midline because loss of the posterior columns is of no relevance.

(D) The myelotomy must be well closed so that the CSF does not run from the subarachnoid space, into the cord and then into the extrathecal drainage site. The use of a small stamp of fascia as shown which may be sutured to the back of the cord is useful to close the myelotomy perfectly after a suture has been placed.

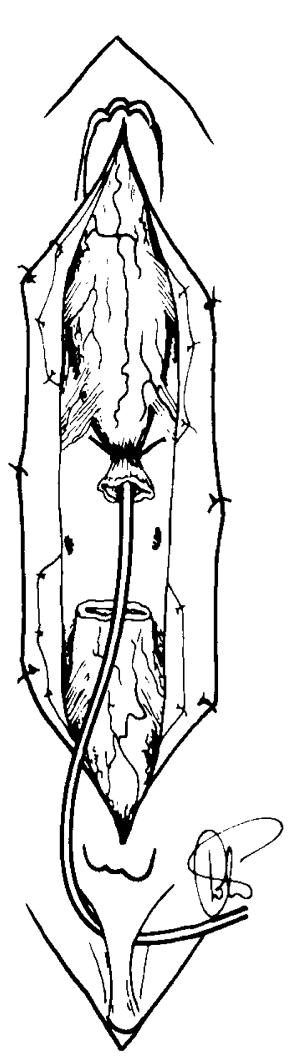

6

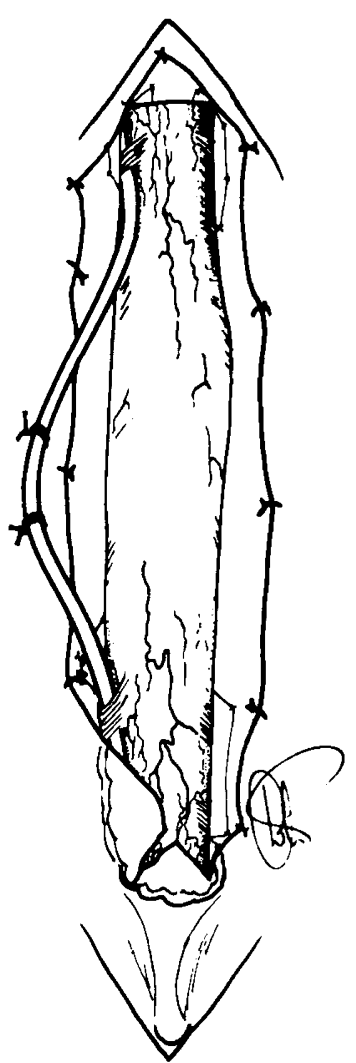

7

Figure 6 If the paraplegia is complete, transection of the cord is the most effective method of fully disabling the filling mechanism. This is obviously inappropriate for incomplete lesions and should be used with care in the lumbar or cervical enlargements. Placement of a drain is easily combined with such a transection.

Figure 7 The CSF pathways may be held open by use of a tube from the subarachnoid spaces above and below the lesion to the meningocele. The incision has been extended upwards and downwards a little way and the method of opening the dura altered to concentrate on the opening of the lateral parts of the pathway. The use of this tube hopefully allows the pressures to equalise between all the compartments concerned and for the energy of the impulses to be dissipated. 


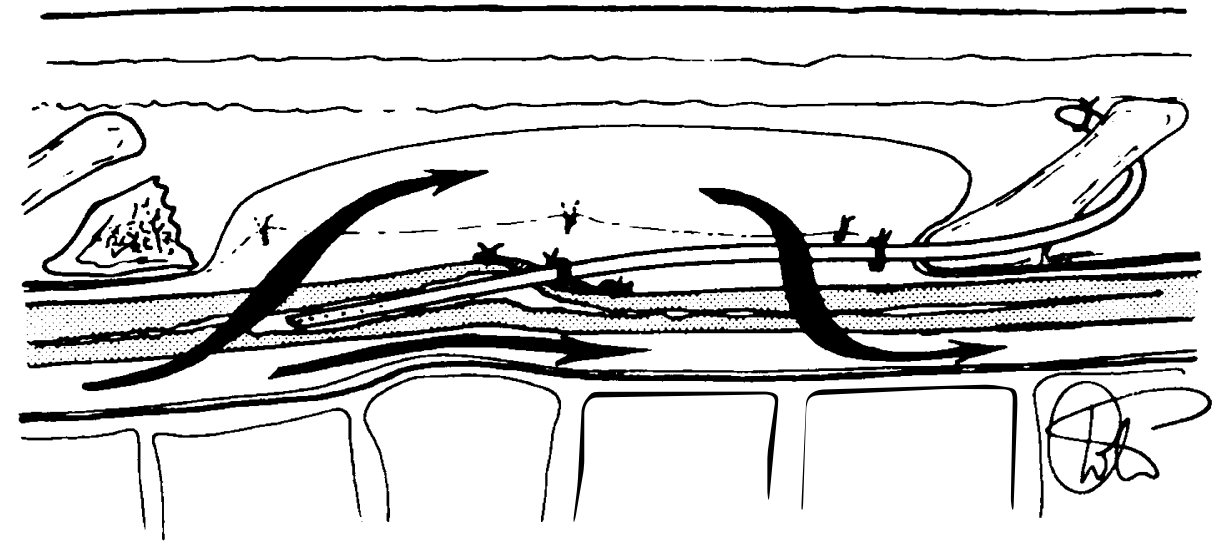

Figure 8 Idealised situation after decompression of the zone of arachnoiditis and formation of an artificial meningocele to allow the free passage of CSF pulsation and a damping action to de-energise the impulses caused by straining.

front of the cord might be adherent to the overlying dura and that the cord might be pulled open by distracting forces imposed upon it by scarring, or when flexion and extension of the bones of the spine occurred then the adhesion of the two parts of the cord might lead to the back of the cord moving upwards and downwards independently of the front. There is a plane of structural weakness across the cord which the syringomyelia cavity commonly finds, and in which the cavity might be initiated.

There are occasional post-traumatic cases where the cavities seem to arise away from the zone of the maximal damage. Such a case was illustrated by Stanworth in 1982. In such a case the fracture level is of course the site of maximal arachnoiditis and neither the liquefaction nor the traction distension ideas seem adequate. Any speculation encounters difficulties in explaining the strong septation which sometimes is found between differing loculi of the syrinx cavity. They sometimes seem to separate the loculi completely, as in case 9 . The assumption that the cavities must communicate or else must have communicated with each other in the past is difficult to resist but proof is lacking. The situation is similar to that which is found with the commoner, hindbrain related forms of syringomyelia, in which the assumption that there was at some stage a communication from the floor of the fourth ventricle to the syringomyelia cavity is popular, and reasonable, as an explanation but remains unproven (Williams, 1980, 1986).

The occurrence of pressure differences between the zone above the arachnoiditis and that below seems to be important. It seems likely that the situation shown in Figure 10 often obtains and that the walls of the cord are partly porous allowing fluid to be forced across the walls during pressure differentials. The behaviour of case 1 with marked improvement after treatment only by opening up the pathways outside the cord seems to support this idea.

The cord is certainly grossly porous in a proportion of these cases; it may weep fluid so fast that the syrinx may go flat within a few minutes of exposure to air in the sitting position. It seems from the behaviour of the intrathecal contrast that the cord forming the walls of a syrinx is largely permeable to small molecules in cases of syringomyelia. 


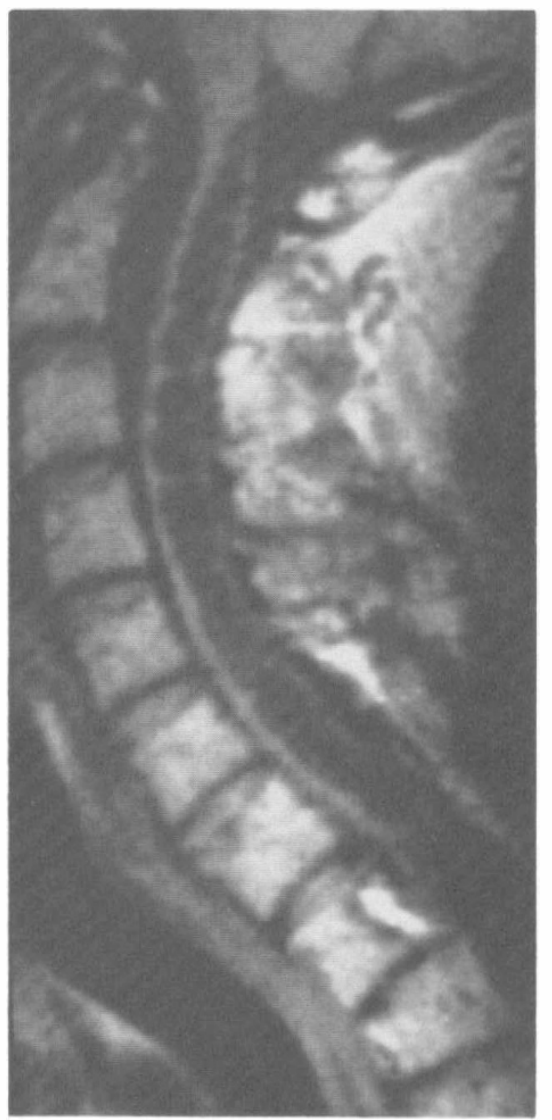

Figure 9 Case 20. Severe syringomyelia ascending as high as the medulla. Note that the cavity not uncommonly ascends to this level whereas in hindbrain hernia cases the constriction of the lower medulla and upper cord provided by the tonsillar herniation usually results in arrest of the upward progression of the cavity at $\mathrm{C} 2$. Communication to the floor of the fourth may be sometimes found at this site.

Once there is a quantity of fluid within the cord of course, the method of advance is probably related to sloshing of fluid (Williams et al., 1981). The surging of the fluid is due to the compression of the dura by rapid distension of the epidural veins and the energy involved is great. When the quantity of fluid within the syrinx is much greater than the volume in the subarachnoid space then the excavation of fluid within the cord has an almost ballistic quality. One of the principles of treatment therefore may be to depulsate the slosh of the spinal fluid, or to pursue the ballistic analogy, to open the breech of the gun by leaving the dura open. Another valuable principle seems to be the leaving of the CSF pathways in free communication so that there are no pressure differentials acting across the walls of the cord. 

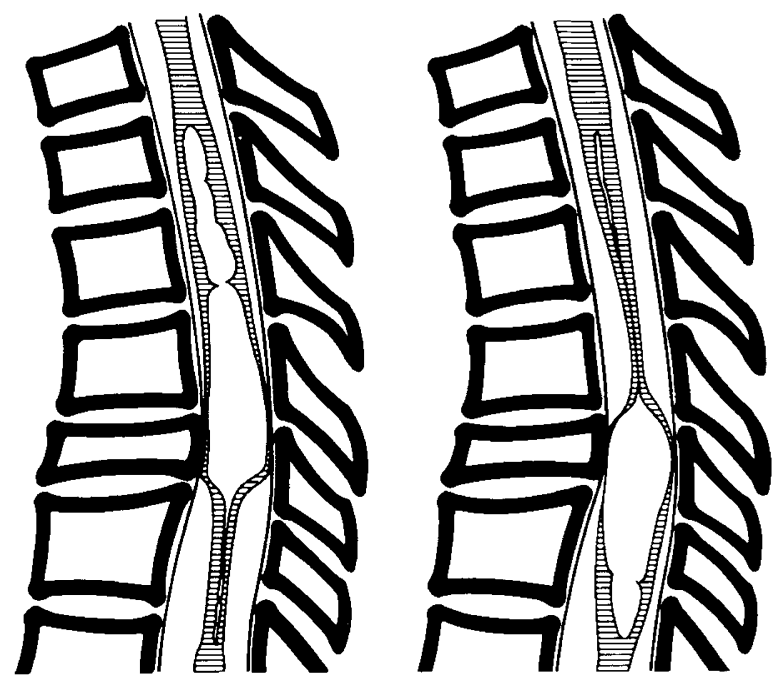

Figure 10 Suggested mechanism for cord filling and propagation of the cavity. The upward movement of CSF as shown on the left, which may occur for example during coughing, produces compression of the bottom part of the syrinx and an upward surge of fluid in the cavity which may cut cephalad in the soft grey matter within the cord. The upward surge of CSF is more energetic than the returning pulsation. There may be a partial evacuation of the lower subarachnoid space by fluid being forced past the constricted subarachnoid space on the outside of the cord. The dropping back of the lesion and the involved cord after the coughing may set up a pressure differential and encourage fluid to enter the cord cavity through the permeable walls of the cord.

\section{Treatment}

The use of syrinx to subarachnoid shunting, although it is frequently successful as reported by McLean et al. (1973) and Barnett and Jousse (1976) and as seen in cases $3,11,12,19,22$ and 23 , may be criticised. There may be some residual elasticity in the cord which allows a myelotomy to deflate a syrinx, but it is clear that the presence of such a hole in the cord may allow a cavity to fill as well as to empty. Such filling is occasionally found as the apparent cause of the intracord cavity (McLean et al., 1973; Savoiardo, 1976). The cavity in the cord in posttraumatic case 1 (Fig. 1, Fig. 2) was apparently filling through such a hole. If the cavity is to be effectively drained then it should probably not be by a variety of myelotomy but by a shunt to a low pressure area such as the pleura or the peritoneum, this view is shared by Peerless and Durward (1983), Barbaro et al. (1984), and La Haye and Batsdorf (1988).

Drainage, by whatever route, may be insufficient, as is illustrated by posttraumatic case 4 . Removal of the cause rather than drainage of the resulting abnormality is preferable. If the cavity is drained it will go flat and parts of the wall may adhere internally and almost certainly block the draining catheter. If there is a filling mechanism still acting, or even if there is a sizeable residual syrinx in another part of the cord then a new syrinx may readily form alongside the flattened syrinx. Healing of the cavity does not prevent another cavity from 
developing alongside it and, as in this case, affecting another part of the cord, indicating that the syrinx changed sides. Treatment should therefore be directed to the treatment of the cause, or specifically to the disablement of the filling mechanism. It is notable that drainage of the cord to the pleura, as is presently recommended, has the additional advantage that the space-occupying qualities of the enlarged cord are lessened and the subarachnoid spaces are opened up after the collapse of the swollen syrinx.

The abolition of the pressure differences and the opening up of the constriction associated with the arachnoiditis or the backward gibbus of damaged bones seems to be of importance. Even in a patient with partial preservation of cord function as in case 1 , the leaving open of the dura and leaving a bypass drain from above the arachnoiditis to below may be associated with marked improvement.

The most effective disablement of the filling mechanism is excision of the area of damaged cord as shown in Figure 6. This recommendation was also made by Durward et al. (1982). The thinned cord through which the CSF almost certainly enters; and the zone of arachnoiditis are thereby removed, the funnel-shaped lower end of the upper syrinx is closed and the drainage tube is conveniently placed. Maximal access to the subarachnoid space of surging fluid is thereby attained. Of the 3 cases with cord transection in this series, none has deteriorated after operation. Of course this technique is limited to complete lesions. The possibility of ascent of the level of complete loss is unacceptable in either the cervical or the lumbar enlargements and since the level of functioning tissue is sometimes difficult to be certain about, transection may be best avoided in patients such as case 8 .

\section{When to treat}

The onset of symptoms may be sudden and involve loss of function which never returns. The complication rate of laminectomy and production of an artificial meningocele must be low, and it seems likely that this will suffice for small syrinxes in partial paraplegics or patients with injuries of the cervical or lumbar enlargements where drainage via a myelotomy might be hazardous. Early treatment therefore has a good deal to commend it.

The sad results in post-traumatic cases 2 and 5, who are the same cases as 2 and 5 in the earlier paper, could almost certainly have been improved if operation had been undertaken at the time of diagnosis.

Post-meningitic case 6 shows that there is probably no safe time for posttraumatic syringomyelia, sudden advance may occur, especially in relation to vigorous straining after many years.

Rossier et al. (1985) made the statement that there was no benefit in operating on a patient with a small syrinx, but all large syrinxes were small at some stage and it seems likely that if they were competently treated then they would not become large syrinxes. Obviously a counsel of perfection would be to treat all cases before they became symptomatic. There is no possibility however of any large series having no post-operative complication rate, and if, for example small syrinxes could be shown sometimes to resolve or to remain asymptomatic frequently, then a waiting policy might be justifiable with small syrinxes which were silent or giving only minimal problems. The state of the remaining cord function is obviously important, post-meningitic case 6 for example had normal 
bladder and sexual function and could walk well enough to get around at work. He was only interested in an operation with no complication rate. This view must deserve sympathy.

\section{Future work}

Further analysis of the surgical material in this series, particularly the correlation of morphological variants such as the type of local cyst, the existence of septations and the odd occurrence of a completely blocked zone at the site of injury with separate cysts below and above, such as that illustrated by Stanworth (1982), may be of interest. Their differing morphology may be correlated with the possibly bimodal distribution of the time of onset of the syrinx after the trauma in the posttraumatic cases.

It is a matter of some urgency to see how many paraplegic cases get small syrinxes, at what age they arise, and how many of them enlarge or become symptomatic, if any prognostic features can be identified from the morphology, and whether early ones may heal. Serial MRI scans from a sizeable population at an early stage may identify what proportion of cases have an early haematoma and what fraction of these then become a clear fluid containing cavity. How many of these then develop a syrinx? In how many cases will a syrinx form without any such seminal cavity?

Routine MRI scans after both conservatively managed paraplegia and those managed with the aid of cord exploration and myelotomy may well yield interesting information in favour of either system. It seems likely that evacuation of a haematoma followed by leaving the dura open will minimise the chances of a syrinx developing. Closure of the dura, in the author's opinion, is like closing the breech of a gun. It reconstitutes the barrel formed by the dura, and enables the fluid which finds its way into the cord to be violently propelled upwards along the inside of the soft grey matter under the influence of violent pressure changes such as coughing, and to excavate new cavities. Non-closure of the dura may be the most important surgical prophylaxis against this group of disorders. The likelihood of syringomyelia, occurring in less than $5 \%$ of paraplegics, of course would not constitute a sole or sufficient indication for cord exploration in the acute stage.

\section{References}

BARbaro NM, Wilson CB, Gutin PH et al. 1984 Surgical treatment of syringomyelia: favourable results with syringoperitoneal shunting. Fournal of Neurosurgery 61:531-538.

BARNETT HJM, JouSSE AT 1976 Post-traumatic syringomyelia (cystic myelopathy). In: VINKEN, BRUYN (eds) Handbook of Clinical Neurology, vol 26 North Holland Publishing Company, pp 113-157.

DURWARD QJ, RICE GP, BALL MJ et al. 1982 Selective spinal cordectomy: clinicopathological correlation. Fournal of Neurosurgery 56:359-367.

Lacert P, Trottier S, Durand J, PANnier S, Grossiord A 1977 Syndromes syringomyeliques tardifs chez la paraplegiques. Revue Neurologique 133(5):325-338.

LA HAYE PA, BATZDORF U 1988 Posttraumatic syringomyelia. Western fournal of Medicine 148:657663.

Mclean DR, Miller JDR, Allen PBR, Ezzedin SA 1973 Post-traumatic syringomyelia. Foumal of Neurosurgery 39:485-492.

PEERLESS SJ, DURWARD QJ 1983 Management of syringomyelia: a pathophysiological approach. Clinical Neurosurgery 30:531-576.

ROSSIER AB, WERNER A, WILDI E, BERNEY J 1968 Contribution to the study of late cervical 
syringomyelia syndromes after dorsal or lumbar traumatic paraplegia. Fournal of Neurology, Neurosurgery and Psychiatry 31:99-105.

Rossier AB, Foo D, SHillito J 1985 Post traumatic cervical syringomyelia. Brain 108:439-461.

SAVOIARDO M 1976 Syringomyelia associated with post-meningitis spinal arachnoiditis. Filling of the syrinx through a communication with the subarachnoid space. Neurology 26:551-554.

Shannon N, Symon L, Logue V, Cull D, Kang J, Kendall BE 1981 Clinical features, investigation and treatment of post-traumatic syringomyelia. Fournal of Neurology, Neurosurgery and Psychiatry 44:35-42.

STANWORTH PA 1982 The significance of hyperhidrosis in patients with post-traumatic syringomyelia. Paraplegia 20:282-287.

SuZuki M, Davis C, Symon L, Gentili F 1985 Syringoperitoneal shunt for treatment of cord cavitation. Fournal of Neurology, Neurosurgery and Psychiatry 48:620-627.

VERNON JD, SILVER JR, SYMON L 1983 Post-traumatic syringomyelia: the results of surgery. Paraplegia 21:37-46.

TATOR CH, MEgURo K, RowEd DW 1982 Favourable results with syringosubarachnoid shunts for treatment of syringomyelia. Fournal of Neurosurgery 56:517-523.

WILliams B 1980 On the pathogenesis of syringomyelia: a review. Fournal of the Royal Society of Medicine 73:798-806.

Williams B, PAGE N 1987 Surgical treatment of syringomyelia with syringopleural shunting. British Fournal of Neurosurgery 1:63-80.

WIlliams B, TERRY AF, JoNes HWF, McSWeEney T 1981 Syringomyelia as a sequel to traumatic paraplegia. Paraplegia 19:67-80.

WILliams B 1986 Progress in syringomyelia. Neurological Research 8:130-145. 